\title{
Therapeutic Potential of IL-17-Mediated Signaling Pathway in Autoimmune Liver Diseases
}

\author{
Haiyan Zhang, ${ }^{1,2}$ Francesca Bernuzzi, ${ }^{1}$ Ana Lleo, ${ }^{1}$ Xiong Ma, $^{2}$ and Pietro Invernizzi ${ }^{1}$ \\ ${ }^{1}$ Liver Unit and Center for Autoimmune Liver Diseases, Humanitas Clinical and Research Center, \\ Via Manzoni 56, Rozzano, 20089 Milan, Italy \\ ${ }^{2}$ State Key Laboratory for Oncogenes and Related Genes, Key Laboratory of Gastroenterology and Hepatology, Ministry of Health, \\ Division of Gastroenterology and Hepatology, Ren Ji Hospital, School of Medicine, Shanghai Jiao Tong University, \\ Shanghai Cancer Institute, Shanghai Institute of Digestive Disease, 145 Middle Shandong Road, Shanghai 200001, China
}

Correspondence should be addressed to Pietro Invernizzi; pietro.invernizzi@humanitas.it

Received 27 February 2015; Accepted 20 May 2015

Academic Editor: Jianfei Yang

Copyright (C) 2015 Haiyan Zhang et al. This is an open access article distributed under the Creative Commons Attribution License, which permits unrestricted use, distribution, and reproduction in any medium, provided the original work is properly cited.

Emerging evidence reveals that various cytokines and tissue microenvironments contribute to liver inflammation and autoimmunity, and IL-17 family is one of highlights acknowledged. Although the implication of IL-17 family in most common autoimmune diseases (such as psoriasis, inflammatory bowel disease, and rheumatoid arthritis) has been extensively characterized, the role of this critical family in pathophysiology of autoimmune liver diseases (AILD) still needs to be clarified. In the review, we look into the intriguing biology of IL-17 family and further dissect on the intricate role of IL-17-mediated pathway in AILD. Considering encouraging data from preclinical and clinical trials, IL-17 targeted therapy has shown promises in several certain autoimmune conditions. However, blocking IL-17-mediated pathway is just beginning, and more fully investigation and reflection are required. Taking together, targeting IL-17-mediated responses may open up new areas of potential clinical treatment for AILD.

\section{Introduction}

Liver is an immunological organ with unique properties of immune tolerance, which can lead to systemic immune tolerance. Many genetically susceptible individuals suffer from autoimmune liver diseases (AILD) while some unidentified environmental factors trigger the breach in immune tolerance resulting liver as a victim. However, the exact pathogenesis of AILD is still unknown. Autoimmune hepatitis (AIH), primary biliary cirrhosis (PBC), primary sclerosing cholangitis (PSC), and autoimmune sclerosing cholangitis are the major forms of AILD. Besides, a proportion of patients within the spectrum of AILD may present with overlapping features of two classical disorders such as AIH, PBC, and PSC. These patients are often referred to as "overlap syndromes" $[1,2]$.

AILD have fluctuating and progressive courses with alternating relapses and quiescences. The spectrum of AILD is diverse, ranging from insidious onset with abnormal liver function tests to fulminant hepatic failure. The causes of these clinical conditions are complex and most likely heterogeneous. The mechanisms responsible for the progression of AILD are yet to be fully clarified. However, recent studies have demonstrated that cytokines play a pivotal role in the induction of immune responses during the development and progression of liver diseases. Among them, IL-17 family is one of the dominant pathogenic components in autoimmune inflammatory diseases, such as multiple sclerosis (MS), psoriasis, and rheumatoid arthritis (RA) [3-5]. Of interest, its role in AILD still requires clarification. On this basis, this review addresses the current data regarding the roles of IL-17 signaling in the pathogenesis of AILD and provides new insight into therapeutic potential of targeting IL-17-mediated responses.

\section{General Features of Interleukin-17}

2.1. IL-17 Family (Discovery, Structure, Resource, and Function). IL-17A (commonly referred to as IL-17) was first identified as a product of rodent activated T cells in 1993 
and was initially known as cytotoxic T lymphocyte associated antigen 8 (CTLA-8) [6]. Since then, other five members of IL-17 family, IL-17B, IL-17C, IL-17D, IL-17E (also called IL25 ), and IL-17F have been discovered based on homology in amino acid sequences [6-9].

IL-17A is the most well investigated member of the IL17 family and acts on multiple cell types to enhance the production of various proinflammatory molecules including cytokines (such as TNF and IL-6), chemokines (such as CXCL2 and MCP-1), mucins acute phase proteins, and matrix metalloproteinases [10-16]. Overall, IL-17A exerts a wide range of functions in autoimmune diseases, host defense, transplantation, allergy, and malignancy [17-21].

With the family, IL-17F is the most homologous protein to IL-17A $(\sim 60 \%)$ and resembles IL-17A in both the cellular sources and regulation function [22]. Interestingly, IL-17A and IL-17F exist as homodimers [10]. In addition, IL-17A and IL-17F also form a heterodimeric cytokine (IL-17A/F) with intermediate signaling potency [23].

Th17, a subset of $\mathrm{CD} 4^{+} \mathrm{T}$ cells named for their ability to preferentially produce IL-17, is recognized as the major producers of IL-17A and IL-17F [24]. In addition, several innate immune cell types are described as sources for IL-17, including $\gamma \delta \mathrm{T}$-cells, natural killer $(\mathrm{NK})$ cells, natural killer $\mathrm{T}$ (NKT) cells, dendritic cells (DCs), activated monocytes, mast cells, neutrophils, and lymph tissue inducer (LTi) cells [2528]. Of note, IL-17A is found to be approximately 10-30 times more potent than IL-17F [29]. However, IL-17F and IL-17A have overlapping yet distinct proinflammatory roles in host immune and defense mechanisms, such as mucoepithelial bacterial infections, inflammatory responses, and allergic diseases [30, 31]. For example, genetic deletion of IL-17F resulted in reduced experimental colitis caused by dextran sulfate sodium, whereas deletion of IL-17A in mice developed more severe intestinal disease [32].

Unlike IL-17F, IL-17E (IL-25) is the most distant cytokine from IL-17A in IL-17 family. Recent studies show that IL17E promotes Th2-mediated immune responses, particularly contributing to airway inflammation and allergic disease [3335].

Far less is known about the cellular sources, receptors/target cells and biological functions of the three remaining other IL-17 family cytokines. IL-17B is expressed in multiple organs, including small intestine, pancreas, spinal cord, and stomach [36]. IL-17C was detected in keratinocytes and tracheal epithelial cells $[37,38]$. Similar to IL-17B, IL$17 \mathrm{D}$ is also expressed in a variety of organs and tissues, including heart, pancreas, and adipose tissue [22]. Recent studies from both human and animal models suggest that these IL-17 family members might possess an important role in inflammatory disease, which highlights the need for further exploration. For instance, IL-17B was observed to participate in a murine model of collagen-induced arthritis whereas treatment with IL-17B neutralizing antibody can successfully suppress arthritis [39].

2.2. IL-17 Receptors (Discovery, Structure, Expression, and Signaling). Interleukin-17RA (also known as IL17R) was the first receptor identified for IL-17A [40]. IL-17RA is expressed in considerable cell types, including endothelial cells, epithelial cells, fibroblasts, and myeloid cells. However, subsequent studies have demonstrated additional receptor members are required to form a functional receptor complex for IL-17 signaling [41]. The IL-17 receptor family represents a group of multimeric proteins that consists of four other molecules, IL-17RB (also known as IL17Rh1), IL-17RC (also known as IL17RL), IL-17RD, and IL-17RE.

Recent studies of IL-17RB revealed the expression in NKT cells, memory Th2 cells, macrophages, lung epithelial cells, airway smooth muscle cells, and endothelial cells [4244]. IL-17RB can bind to both IL-17B and IL-17E in vitro and actively participate in Th2 immune responses via IL17E-IL-17RB interaction, particularly in airway inflammation [33]. Besides, genetic and biochemical studies indicate IL$17 \mathrm{RB}$ binding to IL-17E recruits IL-17RA to the complex in mediating IL-17E function [45].

IL-17RC was initially identified based on sequence homology to IL-17RA [46]. IL-17RC was found to share expression with IL-17RA in multiple cells, including epithelial cells, macrophages, and fibroblasts, but its expression on myeloid cells is much lower [47]. Of note, the assembly of a heterodimeric complex between IL-17RA and IL-17RC is required for the biological signaling of IL-17A and IL-17F. Nevertheless, IL-17RC may have some functions independent of IL-17RA; for IL-17RC expression is elevated in some organs and tissues such as small intestine and lung where the expression of IL-17RA is absent [30].

IL-17RD and IL-17RE were also identified through database mining; however, little is currently known about these two orphan receptors. Studies have discovered the expression of IL-17RD in epithelial cells and endothelial cells. Moreover, IL-17RD can pair with IL-17RA to mediate IL17A signaling while mutations of the IL-17RD cytoplasmic domain can suppress IL-17A function [48]. On one side, IL17RE RNA could be detected in lung, testis, kidney, stomach, and intestine; on the other side, the cellular expression of IL$17 \mathrm{RE}$ is poorly understood. Further studies will be needed to address the significance of IL-17RE [49].

These single-pass receptors share minimal structural homology, including a single transmembrane domain, an extracellular-fibronectin III-like (FnIII) domain, and an intracellular SEF/IL-17R (SEFIR) domain $[29,50]$. As IL17R proteins possess the conserved SEFIR domain, with IL17 family ligands binding, this intracellular domain can directly interact with adaptor protein, ACT1 (also known as TRAF3IP2) to initiate signaling cascades, augmenting various inflammatory molecules that participate in immune responses. For instance, with the help of both ACT1 and TNF receptor associated factor 6 (TRAF6), the binding of IL-17A to IL-17RA can activate nuclear factor $-\kappa \mathrm{B}(\mathrm{NF}-\kappa \mathrm{B})$ signaling pathway [51]. Additionally, IL-17A can activate the CCAAT/enhancer binding proteins (C/EBPs) $\mathrm{C} / \mathrm{EBP} \beta$ and $\mathrm{C} / \mathrm{EBP} \delta$ to induce the transcription of inflammatory gene such as IL-6 [13]. By contrast, IL-17R-Act1-TRAF-NF- $\kappa$ B pathway can be negatively regulated by the binding of TRAF3 to IL-17R, resulting in suppression of downstream signaling [52]. 
TABLE 1: Pathophysiological findings on IL-17 pathway in the development of AILD.

\begin{tabular}{|c|c|c|c|}
\hline Disease type & Sources & Main findings & References \\
\hline \multirow{7}{*}{$\mathrm{AIH}$} & \multirow{5}{*}{ Patients } & $\begin{array}{l}\text { Elevated levels of IL-17 and IL-23 in serum. Increased Th17 cells in } \\
\text { peripheral blood }\end{array}$ & {$[53,54]$} \\
\hline & & Infiltration of Th17 cells with enhanced ROR- $\gamma$ t expression in liver & {$[53]$} \\
\hline & & $\begin{array}{l}\text { Increased expression of IL-17-related cytokines (IL-23, IL-21, IL-1 } \beta \text {, and } \\
\text { IL-6) in liver }\end{array}$ & {$[53]$} \\
\hline & & Impairment of CD $39^{\text {pos }}$ Tregs to suppress IL-17 pathway & {$[55]$} \\
\hline & & Greater proportions of $\mathrm{IL}-17^{+}$and $\mathrm{ROR} \gamma^{+}$cells in ngTregs & {$[56]$} \\
\hline & \multirow{2}{*}{ Mouse models } & Elevated IL-17 levels in liver and serum & {$[54]$} \\
\hline & & Blockade of IL-17 attenuate inflammatory liver injury & {$[54]$} \\
\hline \multirow{11}{*}{$\mathrm{PBC}$} & \multirow{6}{*}{ Patients } & $\begin{array}{l}\text { Elevated levels of IL-17-related cytokines (IL-17, IL-23, IL-1 } \beta \text {, and IL-6) and } \\
\text { enhanced gene expression of IL-17-mediated signalling pathway (IL-23 p19, } \\
\text { IL-23R, and IL-17) in serum }\end{array}$ & {$[57,58]$} \\
\hline & & $\begin{array}{l}\text { Expansion of Th17 cells with enhanced ROR- } \gamma \text { t expression in peripheral } \\
\text { blood }\end{array}$ & {$[57]$} \\
\hline & & Aggregation of Th17 cells around interlobular bile ducts & {$[59-61]$} \\
\hline & & $\begin{array}{l}\text { Enhanced expression of Th17-related cytokines and their cognate receptors } \\
\text { (IL-23p19, IL-23p40, IL-17, and IL-23R) in liver }\end{array}$ & [61] \\
\hline & & $\begin{array}{l}\text { Induction of inflammatory cytokines and chemokines (IL-6, IL-1 } \beta \text {, } \\
\text { IL-23p19, CXCL1, CXCL2, CXCL3, CXCL6, CXCL8, CCL2, and CCL20) by } \\
\text { IL-17 in human BECs }\end{array}$ & {$[60]$} \\
\hline & & Upregulation of MIP-3 $\alpha$ in human BECs for further recruit of LCs & {$[62]$} \\
\hline & \multicolumn{3}{|l|}{ Mouse models } \\
\hline & \multirow{2}{*}{ IL-12R $\alpha-/-$ mice } & Increased frequencies of IL-17 producing cells in liver & {$[63]$} \\
\hline & & Induction of IL-17 responses by splenic CD $4^{+} \mathrm{T}$ cells cocultured with NPCs & [59] \\
\hline & 2OA-BSA-immunized mice & $\begin{array}{l}\text { Reduction of biliary damage in IL-17A-/- mice and IL-22-/- mice. Lower } \\
\text { levels of AMA in IL-17A-/- mice }\end{array}$ & {$[64]$} \\
\hline & dnTGF $\beta$ RII mice & $\begin{array}{l}\text { Lower titres of anti-gp } 210 \text { antibodies in mice with deletions of IL-17-related } \\
\text { cytokines (IL-12p40, IL-23p19, IL-17, IL-6, and TNF- } \alpha \text { ) }\end{array}$ & {$[65]$} \\
\hline \multirow{8}{*}{ PSC } & \multirow{3}{*}{ Patients } & $\begin{array}{l}\text { Infiltration of IL- } 17^{+} \text {lymphocytes around damaged bile ducts and in areas } \\
\text { of neoductular proliferation }\end{array}$ & {$[66]$} \\
\hline & & $\begin{array}{l}\text { Increased frequencies of Th17 cells by stimulation of pathogen in peripheral } \\
\text { blood }\end{array}$ & {$[67]$} \\
\hline & & Induction of Th17 cells by the selective stimulation of TLR 5 and TLR 7 & {$[66]$} \\
\hline & \multirow{5}{*}{ Mouse models (BDL) } & Elevated levels of IL-17A in serum & {$[68]$} \\
\hline & & $\begin{array}{l}\text { Increased gene levels of IL-17-related cytokines and receptors (IL-17 A, } \\
\text { IL-17F, IL-17RA, and IL-17RC) in liver }\end{array}$ & {$[68]$} \\
\hline & & Reduction of BDL-induced liver fibrosis in IL-17RA-/- mice & [68] \\
\hline & & $\begin{array}{l}\text { Strong expression of IL-17-related cytokines and their receptors in liver } \\
\text { resident cells (Kupffer cells, HSC) }\end{array}$ & {$[68,69]$} \\
\hline & & $\begin{array}{l}\text { Induction of TNF- } \alpha \text { and TGF- } \beta \text { in Kupffer cells by IL-17 and in turn } \\
\text { promotion of IL-17 expressing cells differentiation }\end{array}$ & {$[68,69]$} \\
\hline
\end{tabular}

\section{Pathological Roles of IL-17 in Autoimmune Liver Diseases}

Before the recognition of the distinct Th17 population, it was considered that Th1, Th2, and B cells were the dominant cellular components of pathology in autoimmunity. However, with the deepening of the studies about IL-17 family, IL-17 has been strongly implicated in the pathogenesis of autoimmune diseases, such as psoriasis, inflammatory bowel disease (IBD), RA, and systemic lupus erythematosus (SLE) [70-73]. Nevertheless, robust evidence demonstrates that autoimmune liver diseases implicate the IL-17 pathway (Table 1).

3.1. Autoimmune Hepatitis. AIH is a chronic inflammatory liver condition of unknown etiology that is putatively 
initiated by the aberrant autoaggressive immunity against hepatocyte-specific autoantigens [57]. AIH is a progressive necroinflammatory disease characterized by elevated aminotransferase levels, hypergammaglobulinemia, circulating autoantibodies, and histological evidence of interface hepatitis [74]. The abnormal autoimmune reactions in $\mathrm{AIH}$ are believed to be orchestrated by self-antigenic peptide activated $\mathrm{T}$ cells that trigger the antibody-mediated cellular cytotoxicity and contribute to the pathogenesis of AIH [75].

Traditionally, AIH has been associated with dysregulations of both innate and adaptive immunity. Recently, IL17 pathway has caught the attention of hepatologists and immunologists for IL-17 that is inimitably positioned at the interface of both types of immunity. A recent study has suggested that the serum levels of IL-17 and IL-23 were significantly higher in patients with $\mathrm{AIH}$ compared to patients with chronic hepatitis $\mathrm{B}(\mathrm{CHB})$ and healthy controls. Moreover, the frequency of circulating Th17 cells and the gene expression of IL-17 in the peripheral blood mononuclear cells (PBMC) of AIH patients were also demonstrated to be substantially elevated when detected by flow cytometry and real-time PCR $[53,54]$. It is important to note that the number of Th17 cells and the gene expressions of IL-17 specific transcription nuclear factor- retinoic-acid-receptorrelated orphan nuclear receptor gamma (ROR- $\gamma \mathrm{t}$ ) also were significantly increased in the liver of AIH patients compared to those with $\mathrm{CHB}$ and healthy controls. Interestingly, hepatic Th17 cells in AIH patients are increased in a disease severity dependent manner. In addition, the expression of IL-17related cytokines, that is, IL-23, IL-21, IL-1 $\beta$, and IL-6, was significantly augmented in the liver of AIH patients [53].

In mouse models of experimental autoimmune hepatitis, congruent findings reported that the expression of IL-17 in the livers and sera of AIH mice were significantly elevated compared to the control mice. It is noteworthy that administration of IL-17A monoclonal neutralizing antibody could markedly reduce histological hepatic necrosis and serum ALT levels compared to controls [54]. These data suggest that IL-17 pathway is likely to be a prime part of AIH pathogenesis.

The mechanisms underlying the breakdown of selftolerance leading to AIH have not been fully elucidated, though numerous lines of evidence indicate that numerical and functional regulatory T-cell (Tregs) defects may play a permissive pathogenic role [76-78]. Accordingly, the disrupted regulatory circuits of Tregs may account for the aberrant dysregulation of IL-17-mediated inflammatory responses. Within the Tregs group, CD39 ${ }^{\text {pos }}$ Tregs have been shown to display specific suppression over IL17 immunity compared to their CD39 ${ }^{\text {neg }}$ counterpart [79]. More recently, studies have reported that CD39 ${ }^{\text {pos }}$ Tregs not only are decreased in frequency but also exhibit limited adenosine triphosphate/adenosine diphosphate hydrolysis activity in AIH patients, which in turn fail to suppress the overactive IL-17 pathway by effector $\mathrm{CD}^{+} \mathrm{T}$ cells [55]. These observations imply that impairment of CD39 ${ }^{\text {pos }}$ Tregs in AIH, an inability to suppress IL-17 production and a propensity to convert to IL-17 producing effectors, may contribute to defected immunosuppression and autoimmune liver condition. Notably, Tregs and Th17 cells share a common progenitor, though their developmental pathways differ. Previous studies have reported that Tregs could be generated from CD25- (ngTreg) cells in AIH patients, which suppress the immune responses less efficiently than the freshly isolated Tregs [80]. More importantly, studies also demonstrated that ngTregs from AIH patients presented the greater proportions of $\mathrm{IL}-17^{+}$and $\mathrm{ROR} \gamma^{+}$cells than Tregs from healthy controls. Furthermore, taking advantage of several different approaches for the removal of IL-17 influence, ngTregs from patients with AIH managed to differentiate into functionally stable immunosuppressive cells [56]. These data highlighted the crucial effect of IL-17 pathway on defeated function of Treg in AIH and laid a solid foundation for immunotherapeutic strategies aiming at reestablishing immune tolerance through Treg infusion in combination with IL-17 abrogation.

3.2. Primary Biliary Cirrhosis. PBC is a chronic inflammatory autoimmune disease that mainly targets the cholangiocytes of the interlobular bile ducts in the liver [81]. The diagnosis of PBC is made when two of the three criteria are fulfilled, that is, presence of serologically PBC-specific autoantibodies such as anti-mitochondrial antibodies (AMA), abnormal changes in biochemical tests indicating cholestasis for longer than 6 months, and histologically chronic nonsuppurative destructive cholangitis followed by progressive bile duct loss [82]. There have been significant advances in the understanding of the immunobiology of $\mathrm{PBC}$ which is regarded as a classical $\mathrm{T}$ cell-mediated autoimmune disease. Intriguingly, various cytokines and tissue microenvironments were shown to exert crucial roles in the regulation and propagation of autoimmune inflammatory responses. Accumulating evidence in mouse models and clinical studies has clearly demonstrated the pivotal involvement of IL-17 signaling pathway in the pathogenesis of PBC.

It has been well described that not only the serum concentrations of IL-17 and IL-17-related cytokines such as IL-23, IL-1 $\beta$, and IL- 6 but also the mRNA expression levels of IL-17-mediated signaling pathway such as IL-23 p19, IL-23R, and IL-17 in PBMCs from PBC patients were significantly elevated compared to the healthy control [57, 58]. Consistent with the IL-17 cytokines profile, peripheral Th17 cell population and IL-17 specific ROR- $\gamma$ t expression of PBC patients were increased markedly compared to patients with $\mathrm{CHB}$. On the contrary, peripheral Treg cell population and the expression of Treg specific transcription nuclear factor FOXP3 were decreased dramatically in patients with $\mathrm{PBC}$ relative to $\mathrm{CHB}$ disease control [57]. These observations strongly imply that the Th17/Treg imbalance appears to exacerbate the breakdown of immune homeostasis in PBC.

One of the intriguing questions in $\mathrm{PBC}$ is that the autoimmune attack is organ specific and the immunological destruction is selective focus on small bile ducts. Consistent with this notion, researchers concern more about the role of IL-17 pathway in the liver of PBC patients. Indeed, several studies have revealed that $\mathrm{PBC}$ patients exhibit elevated levels of hepatic IL- $17^{+}$infiltrates as compared with healthy livers $[59,60]$. Of interest, our recent results address the extensive IL-17-associated cytokines microenvironment 
specifically in the livers of $\mathrm{PBC}$ and non- $\mathrm{PBC}$ control liver disease patients. Our observations have demonstrated that Th17-related cytokines and their cognate receptors, that is IL23p19, IL-23p40, IL-17, and IL-23R, were expressed by the inflammatory cells localized to the portal tracts, with the IL$17^{+}$cells aggregated around interlobular bile ducts intensively. More importantly, Th17 skewing was more prominent in advanced PBC patients [61]. This direct association of Th17 skewing with disease severity uncovers the significance of the IL-23/Th17 pathway in the perpetuation of the so-called traditional IL-12/Th1-mediated immunopathology in PBC.

Of noted importance is that small biliary epithelial cells (BECs) are regarded as the target cells of the autoimmune destruction in PBC [83]. Thus, numerous studies aim to unravel the contribution of IL-17 pathway on the pathogenesis of cholangiopathy. Interestingly, BECs possess IL-17receptors (IL-17RA and IL-17RC) and also Actl (an essential adaptor protein in IL-17-mediated signaling). By taking advantage of the cultured human BECs, stimulation with IL17 could induce the production of inflammatory cytokines (IL-6, IL-1 $\beta$, and IL-23p19) and chemokines (CXCL1, CXCL2, CXCL3, CXCL6, CXCL8, CCL2, and CCL20) [60]. These evidences have indicated that periductal secreton of IL-17 facilitate the migration of various inflammatory cells including Th17 cells, which in turn aggravate the chronic cholangitis and bile duct damage in PBC. Moreover, a subsequent study demonstrated that Langerin ${ }^{+}$Langerhans cells (LCs), which were dominantly scattered around or within biliary epithelial layers of the damaged bile ducts, served as periductal antigenpresenting cells in PBC [84]. IL-17 managed to upregulate the expression of macrophage inflammatory protein- $3 \alpha$ (MIP$3 \alpha$ ) in human BECs dramatically, while MIP- $3 \alpha$ is the main chemokine for attracting and recruiting LCs [62]. Collectively, IL-17 pathway exerts as an unneglectable component of the periductal cytokine milieu and biliary innate immunity in PBC.

Detailed studies in several well-characterized murine models of PBC have further confirmed the importance of IL17 signaling pathway in the development and progression of PBC. To begin with, IL-2 receptor $\alpha$ knockout mice, one of the identified murine models manifesting characteristic clinical features of human PBC, exhibits increased frequencies of IL17 producing cells in the liver [63]. Similar to PBC patients, IL-2R $\alpha \mathrm{KO}$ mice also demonstrate aggregative IL- $17^{+}$staining in diseased portal areas compared to control. Notably, splenic $\mathrm{CD}^{+} \mathrm{T}$ cells cocultured with liver nonparenchymal cells (NPCs) from wild-type mice could augment IL-17 production approximately 10-fold compared to T cells alone [59]. These data suggest a novel connection between the induction of IL-17 responses and unique liver environment mediated by liver NPCs and IL-17-related cytokine milieus in cases of liver autoimmunity.

Secondly, 2-octynoic acid-BSA-immunized mice that develop an intense inflammatory cholangitis with similarities to humans with PBC are another classical PBC animal model. In some unique gene-deleted mice immunized with 2OABSA, it is interesting to find that deletion of IL-17A and IL-22, instead of IL-17F could attenuate biliary damage and inflammation. Moreover, reduced levels of AMA were detected in
IL-17A-knockout mice compared with controls [64]. These finding propose a potential therapeutic intervention of IL-17 pathway for PBC.

Additionally, dominant-negative TGF- $\beta$ receptor II (dnTGF $\beta$ RII) mice are also one of the well-established spontaneous models that exhibit histological features of $\mathrm{PBC}$ with the same AMA specificity [85]. It is important to note that considerable patients with $\mathrm{PBC}$ have detectable serum ANA directed primarily against gp210 and sp100. Upon further investigation, it was revealed that sera from dnTGF $\beta$ RII mice contained antibodies against gp210 and sp100. However, mice with germline deletions of the genes encoding IL-17-related cytokines, that is, IL-12p40, IL-23p19, IL-17, IL-6, and TNF- $\alpha$, had dramatically lower titres of anti-gp210 antibodies, but not anti-sp100 antibodies [65]. In fact, several lines of suggestive evidence mentioned that positive-anti-gp210 antibodies often predict a hepatic failure type of progression in PBC $[86,87]$. Deletion of those IL17-related cytokines that led to significantly lower serum anti-gp210 titres suggests that Th17 cells appear to orchestrate anti-gp210 generation. Taken together, these observations provide a clue to further dissect the possible interaction between IL-17 inflammatory responses and the appearance of $\mathrm{PBC}$-specific autoreactivity.

3.3. Primary Sclerosing Cholangitis. PSC is a rare chronic cholestatic liver disease characterized by diffuse inflammation, destruction, and fibrosis of multifocal bile ducts leading to strictures predominantly in large- and medium-sized ducts of the biliary tree $[88,89]$. At present, the critical etiology or the conclusive pathogenic mechanisms underlying PSC remain unclear. Numerous hypotheses have emerged and it has been widely accepted that abnormality of hepatic immune response contribute to initiation and progression of fibro-obliterative cholangiopathy [90, 91]. Recent evidence has revealed that Th17 cells and its canonical cytokine IL17 are served as critically important contributors of PSC pathogenesis.

It has recently been described the numbers of $\mathrm{IL}-17^{+}$ lymphocytes in liver were significantly increased in PSC patients compared to AIH control patients. Additionally, IL-17A-expressing $\mathrm{T}$ cells aggregated around damaged bile ducts and in areas of neoductular proliferation [66]. It is increasingly recognized that dysregulated responses to pathogen stimulation, especially bacteria and fungi, may be the proximal contributor to the immune activation in PSC $[67,92]$. Of significance, PBMCs from PSC patients manifested significantly increased frequencies of Th17 cells after pathogen stimulation compared to healthy controls and cholestatic controls. Interestingly, stimulation with Candida albicans, which was shown to have a negative effect on progression of disease, gained the highest frequencies of Th17 cells than other pathogens in PSC patients [67]. Furthermore, Th17 induction were noted by the selective stimulation of Toll-like receptors (TLR) 5 and 7, indicating that the pattern recognition receptors signaling pathways may intimately be involved in this response [66]. These evidence points to the speculation that aberrant exposure to pathogens in bile potentially lead to a robust induction of IL-17 responses, 
which could initiate and then perpetuate portal and biliary inflammation in PSC.

By using several currently available animal models resembling some individual characteristic hallmarks of human PSC, researchers can therefore obtain a better knowledge of IL-17 pathway. Experimental biliary obstruction models, such as bile duct ligation (BDL), share the cardinal features of obstructive cholestasis and biliary fibrosis with human PSC $[93,94]$. Consistent with the reports from PSC patients, both the gene levels of IL-17-related cytokines and receptors (IL-17 A, IL-17F, IL-17RA, and IL- 17RC) in the livers and sera concentration of circulating IL-17A in BDL mice were strongly upregulated compared with their sham control. More importantly, BDL-induced liver fibrosis was apparently inhibited in IL-17RA-/- mice compared with their wild-type counterparts, manifested by a sharp decrease of collagen deposition, $\alpha$-SMA ${ }^{+}$myofibroblasts number and mRNA expression of fibrogenic gene, and so forth [68]. Intriguingly, liver resident cells such as Kupffer cells and hepatic stellate cells (HSC) can also show strong expression of IL-17 cytokines and their receptors in addition to Th17. Furthermore, IL-17 could stimulate the production of TNF$\alpha$ and TGF- $\beta$ from Kupffer cells, which then regulate the HSC activation via the Stat-3 signaling pathway and in turn promote the differentiation of IL-17 expressing cells $[68,69]$. To date, however, there is no ideal single animal model that can demonstrate that all the characteristic of PSC patients exists. Therefore, we will rather call for more different models to elucidate the particular immune role of IL17/IL17R signaling within the pathogenetic steps of PSC.

\section{Therapeutic Potential of IL-17-Mediated Signaling Pathway in Autoimmune Liver Diseases}

As the studies mentioned above, excessive IL-17 responses have been proven to be a key mediator and potent drivers of liver-specific autoimmune diseases. With these comments in mind, targeting dysregulated IL-17 signaling pathway seems to be a new area of promising immunotherapy for AILD patients, especially for those patients who failed to respond to conventional therapy. However, detailed studies on the potential of adjusting violent IL-17 responses in AILD remain limited. On the other hand, it is also clear that pathological IL-17-mediated signaling is generally involved in many other human autoimmune conditions such as psoriasis, IBD, RA, SLE, and MS to name a few [3, 95-98]. Inspiringly, numerous clinical studies have examined the feasibility and effectiveness of reconstituting IL-17-mediated pathways including targeting IL-17-related cytokines/receptors, regulating the expression of IL-17 cytokines and IL-17/IL-17R downstream signaling for therapeutic purposes (Figure 1).

4.1. Blocking IL-17/IL-17 Receptors. Among different options for targeting IL-17 pathway, blocking IL-17 or IL-17R family, tend to be the most direct strategy. Thus, accumulating evidences stem from cellular, animal, and human studies uncovered the beneficial anti-inflammatory effect of blocking IL-17/IL-17 receptors on attenuating autoimmune diseases [99]. These encouraging results of targeting IL-17/IL-17R attract the attention of many medicine companies, and the predominant studies prefer to focus on IL-17A and IL17RA. Blocking agents that neutralize IL-17A (e.g., secukinumab/AIN457, ixekizumab/LY2439821) and IL-17RA (e.g., brodalumab/AMG-827) are on track to Phase II/III clinical trials with satisfactory data. Taking treating psoriasis patients for example, all the published Phase II, randomized, doubleblind, placebo-controlled studies results from these three humanized monoclonal antibodies offer encouragement, with the majority of ( $82 \%$ for secukinumab versus $9 \%$ for placebo, $P<0.001 ; 82.8 \%$ for ixekizumab versus $7.7 \%$ for placebo, $P<0.001 ; 86.3 \%$ for brodalumab versus $16.0 \%$ for placebo, $P<0.001)$ patients obtaining at least $75 \%$ improvement from baseline in the Psoriasis Area and Severity Index score (PASI 75) after 12 weeks of treatment [100-102]. Furthermore, Phase III results demonstrated that secukinumab not only significantly improved the clinical symptoms of psoriasis at 12 weeks but also offer faster yet longer efficacy than etanercept (TNF inhibitor) and placebo control [103]. Favorable findings were also reported in the clinical trial of secukinumab and ixekizumab with satisfactory relief of symptoms and safety in various IL-17related autoimmune disease states, such as RA, ankylosing spondylitis, and noninfectious uveitis [104-107]. However, it is noteworthy that secukinumab is ineffective and has higher rates of adverse events for treating patients with moderate to severe Crohn's disease [108]. This unfavorable data alarm us to give more cautious consideration on IL-17 antibody before comprehensive clinical application.

Regarding targeting IL-17/IL-17R family, there are other members under the consideration. In the light of three different forms of IL-17 complex exist, that are IL-17A/IL17A homodimer, IL-17F/IL-17F homodimer, and IL-17A/IL17F IL-17A/IL-17A heterodimer. Researchers aim to target both IL-17A and IL-17F by using the same antibody RG7624 (Roche) to assess the efficacy and safety in the clinical trial. However, to the best of our knowledge, there have not been any published data from RG7624 Phase I trial. Concerning targeting IL-17 receptor, IL-17RC is believed to be another potential strategy in addition to IL-17RA. As IL-17RA and IL17RC heterodimer function as the indispensable component of IL-17A and IL-17F signaling pathway [109], the therapeutic tool blocking both IL-17 RA and IL-17RC gains the attention. In concordance, previous study demonstrated that both IL17RA and IL-17RC were implicated in the IL-17-triggered inflammatory cascade and blockade of both receptors by silencing interfering RNA or specific inhibitors was essentially needed to downregulate IL-17 pathogenic responses in RA [110]. Nevertheless, targeting IL-17RA may lead to undesirable effect on the IL-17E-mediated responses with IL17RA/IL-17RB heterodimer as receptor for IL-17E [111]. In view of anti-inflammatory effect of IL-17E in inflammatory autoimmune disorders, thus targeting IL-17RC may be a more specific and efficient strategy. 


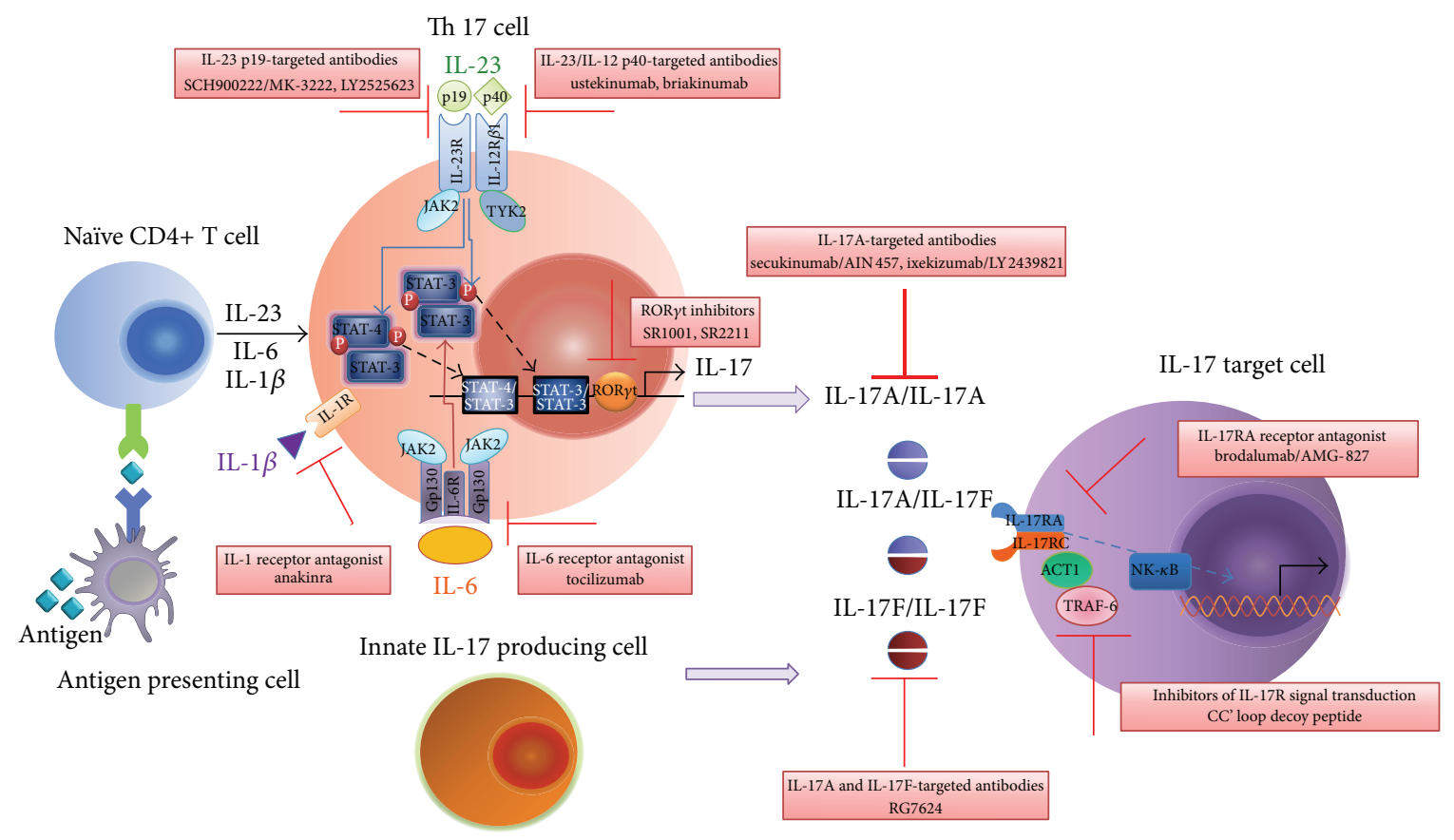

FIGURE 1: Therapeutic potential of targeting IL-17-mediated pathway. Several novel strategies in which members of the IL-17 family can be targeted are already in use for preclinical and clinical trials, including inhibitors blocking the differentiation of TH17 cells, IL-17 family cytokines or their cognate receptors-targeted antibodies and small molecule inhibitors blocking transduction of IL-17-mediated signaling in target cells.

4.2. Targeting Upstream of $I L-17$. New therapies inhibiting upstream of IL-17-mediated pathways have been proposed as attractive avenues of investigation. Several proinflammatory cytokines, IL-23, IL-6, and IL- $1 \beta$ in particular, are crucial for the development of IL-17-expressing cells and thus provoke the induction of IL-17 cytokines. Accordingly, clinical trials hold promise for targeting of these cytokines or their receptors as therapies of certain autoimmune diseases. First of all, neutralization antibody against the p40 chain of IL-23/IL-12 (ustekinumab and briakinumab) presented satisfactory efficacy and sustained safety in Phase II/III clinical trials for treating patients with active psoriatic arthritis or refractory Crohn's disease [112, 113]. More importantly, ustekinumab yielded desirable long-term safety in patients with moderate-to-severe psoriasis up to 5 years of follow-up in large approved Phase III trials [114, 115]. Given the fact that the p40 subunit is shared by IL-23 and IL-12, antibodies (SCH900222/MK-3222 and LY2525623) aiming at IL-23 unique subunit p19 should be more specific. Presently, the clinical trials of these two antibodies are still in process [116].

Secondly, IL- 6 also participates in the induction of Th17 cells which are major source of IL-17A and IL-17F. Antagonistical antibody against the interleukin 6 receptor (tocilizumab) demonstrates significant clinical efficacy and satisfying safety; hence tocilizumab has been approved in many countries for the treatment of certain inflammatory autoimmune diseases such as RA and juvenile idiopathic arthritis (JIA) $[117,118]$. In addition, IL- $1 \beta$ is another crucial cytokine for IL-17 induction. Of significant, IL-1 receptor antagonist (anakinra) has emerged as a promising clinical treatment for RA [119].

It has been widely accepted that ROR $\gamma \mathrm{t}$ serve as the master regulator for Th17 differentiation. Therefore, this renders us a clue that ROR $\gamma$ t has the potential to be a promising therapeutic target for autoimmune disease. Actually, ROR $\gamma \mathrm{t}-$ specific inhibitors are on the way to become one of the most competitive biological drugs among all therapeutic fields. Emerging studies have focus on the drug target with several favorable candidates for further development [120-122]. Of relevance, SR1001, a high-affinity dual ROR $\alpha$ and ROR $\gamma$ inverse agonist has been proved to effectively suppress the clinical severity of experimental autoimmune encephalomyelitis (a well-characterized model of multiple sclerosis) through its inhibition on TH17 cell differentiation [123]. It is noteworthy that $\operatorname{ROR} \alpha$ and $\operatorname{ROR} \gamma$ exert extra functions outside of the immune system and are the important modulators of hepatic metabolism. As $\operatorname{ROR} \alpha$ is the positive regulator of hepatic metabolic gene such as Rev-erb $\alpha$, PAI-1, and Cyp7b1, administration of SR1001 may have broad implications in metabolic homeostasis [123-126]. Therefore, new inhibitors that are more specific to ROR $\gamma \mathrm{t}$ should be thoughtfully selected before further usage in autoimmune liver disease treatment. In concordance, SR2211, a potent $\operatorname{ROR} \gamma$ modulator which demonstrate selectively inhibitory effect on the production of IL-17 in cells, is seen as a potentially viable approach for treating autoimmune disorders [127]. 
4.3. Targeting Downstream Signaling of IL-17. Downstream targets of IL-17/IL-17R initiated signaling pathways are also promising candidates to inhibit their proinflammatory activity. Of note, the genetic variation of the Actl gene (TRAF3IP2), which is the key adaptor to propagate IL-17mediated downstream signaling, is associated with susceptibility to psoriasis and psoriatic arthritis by genome-wide association studies (GWAS) $[128,129]$. As a first step to target Actl for therapeutic strategies, recent study reported that blocking the interaction between Actl and IL-17RA with a CC' loop decoy peptide significantly attenuated IL-17-A and IL-17E-associated inflammation [130]. These observations suggest the potential of blocking Actl for management of IL-17-induced autoimmune diseases. Moreover, crucial transcription factors such as NF- $\kappa \mathrm{B}, \mathrm{C} / \mathrm{EBP}$, and AP-1 [131] involved in regulating IL-17 signaling events deserve more attention and further investigation as the next generation of efficacious therapies targets.

\section{Conclusions}

IL-17 family has been shown to play active and essential roles in the pathogenesis of AILD by controlling numerous immune mediators and cellular events. Therefore, blocking IL-17-induced responses at an early stage should prevent these inflammatory events to occur or exacerbate. The discovery of IL-17 target therapy has opened up new areas of potential clinical treatment, with several clinical trials showing encouraging results. However, given the complexity of immunological interactions, more intensive investigation and cautious reflection are required. Nevertheless, there are still many key questions remaining with regard to other members of IL-17 family besides IL-17A and IL-17F. Of noted importance is that inhibition of IL-17, similar to blockade of TNF- $\alpha$ cytokine, could raise the potential risks of serious infection and other unexpected conditions. Therefore, the optimal blockade place of IL-17 pathway should properly balance therapeutic benefits and side effects in human autoimmune disease management.

\section{Abbreviations}

$\begin{array}{ll}\text { AILD: } & \text { Autoimmune liver diseases } \\ \text { AIH: } & \text { Autoimmune hepatitis } \\ \text { PBC: } & \text { Primary biliary cirrhosis } \\ \text { PSC: } & \text { Primary sclerosing cholangitis } \\ \text { CHB: } & \text { Chronic hepatitis B } \\ \text { MS: } & \text { Multiple sclerosis } \\ \text { RA: } & \text { Rheumatoid arthritis } \\ \text { NK: } & \text { Natural killer } \\ \text { DCs: } & \text { Dendritic cells } \\ \text { Lti: } & \text { Lymph tissue inducer } \\ \text { BEC: } & \text { Biliary epithelial cells } \\ \text { MIP-3 } \alpha: & \text { Macrophage inflammatory protein-3 } \alpha \\ \text { LC: } & \text { Langerhans cells } \\ \text { NPCs: } & \text { Nonparenchymal cells } \\ \text { AMA: } & \text { Anti-mitochondrial antibodies } \\ \text { dnTGF } \beta \text { RII: } & \text { Dominant-negative TGF- } \beta \text { receptor II } \\ \text { TLR: } & \text { Toll-like receptor } \\ \text { BDL: } & \text { Bile duct ligation }\end{array}$

HSC: Hepatic stellate cells

2OA: 2-Octynoic acid

TRAF6: TNF receptor associated factor 6

NF- $\kappa \mathrm{B}:$ Nuclear factor $-\kappa \mathrm{B}$

IBD: Inflammatory bowel disease

SLE: Systemic lupus erythematosus.

\section{Conflict of Interests}

The authors declare that no financial conflict of interests exists.

\section{References}

[1] O. Chazouillères, D. Wendum, L. Serfaty, S. Montembault, O. Rosmorduc, and R. Poupon, "Primary biliary cirrhosisautoimmune hepatitis overlap syndrome: clinical features and response to therapy," Hepatology, vol. 28, no. 2, pp. 296-301, 1998.

[2] K. M. Boberg, R. W. Chapman, G. M. Hirschfield, A. W. Lohse, M. P. Manns, and E. Schrumpf, "Overlap syndromes: the International Autoimmune Hepatitis Group (IAIHG) position statement on a controversial issue," Journal of Hepatology, vol. 54, no. 2, pp. 374-385, 2011.

[3] J. S. Tzartos, M. A. Friese, M. J. Craner et al., "Interleukin-17 production in central nervous system-infiltrating $\mathrm{T}$ cells and glial cells is associated with active disease in multiple sclerosis," The American Journal of Pathology, vol. 172, no. 1, pp. 146-155, 2008.

[4] M. A. Lowes, T. Kikuchi, J. Fuentes-Duculan et al., "Psoriasis vulgaris lesions contain discrete populations of Th1 and Th17 T cells," Journal of Investigative Dermatology, vol. 128, no. 5, pp. 1207-1211, 2008.

[5] G. Azizi, F. Jadidi-Niaragh, and A. Mirshafiey, "Th17 Cells in Immunopathogenesis and treatment of rheumatoid arthritis," International journal of rheumatic diseases, vol. 16, no. 3, pp. 243-253, 2013.

[6] E. Rouvier, M.-F. Luciani, M.-G. Mattei, F. Denizot, and P. Golstein, "CTLA-8, cloned from an activated T cell, bearing AUrich messenger RNA instability sequences, and homologous to a Herpesvirus saimiri gene," Journal of Immunology, vol. 150, no. 12, pp. 5445-5456, 1993.

[7] T. Starnes, H. E. Broxmeyer, M. J. Robertson, and R. Hromas, "Cutting edge: IL-17D, a novel member of the IL-17 family, stimulates cytokine production and inhibits hemopoiesis," The Journal of Immunology, vol. 169, no. 2, pp. 642-646, 2002.

[8] J. Lee, W.-H. Ho, M. Maruoka et al., "IL-17E, a novel proinflammatory ligand for the IL-17 receptor homolog IL-17Rh1," The Journal of Biological Chemistry, vol. 276, no. 2, pp. 1660-1664, 2001.

[9] S. G. Hymowitz, E. H. Filvaroff, J. Yin et al., "IL-17s adopt a cystine knot fold: structure and activity of a novel cytokine, IL17F, and implications for receptor binding," The EMBO Journal, vol. 20, no. 19, pp. 5332-5341, 2001.

[10] F. Fossiez, O. Djossou, P. Chomarat et al., "T cell interleukin17 induces stromal cells to produce proinflammatory and hematopoietic cytokines," Journal of Experimental Medicine, vol. 183, no. 6, pp. 2593-2603, 1996.

[11] S. C. Liang, X.-Y. Tan, D. P. Luxenberg et al., "Interleukin (IL)22 and IL-17 are coexpressed by Th17 cells and cooperatively 
enhance expression of antimicrobial peptides," The Journal of Experimental Medicine, vol. 203, no. 10, pp. 2271-2279, 2006.

[12] M. B. M. Teunissen, C. W. Koomen, R. de Waal Malefyt, E. A. Wierenga, and J. D. Bos, "Interleukin-17 and interferon$\gamma$ synergize in the enhancement of proinflammatory cytokine production by human keratinocytes," Journal of Investigative Dermatology, vol. 111, no. 4, pp. 645-649, 1998.

[13] F. Shen, Z. Hu, J. Goswami, and S. L. Gaffen, "Identification of common transcriptional regulatory elements in interleukin-17 target genes," The Journal of Biological Chemistry, vol. 281, no. 34, pp. 24138-24148, 2006.

[14] S. Dragon, M. S. Rahman, J. Yang, H. Unruh, A. J. Halayko, and A. S. Gounni, "IL-17 enhances IL-1 $\beta$-mediated CXCL-8 release from human airway smooth muscle cells," The American Journal of Physiology - Lung Cellular and Molecular Physiology, vol. 292, no. 4, pp. L1023-L1029, 2007.

[15] W. H. Faour, A. Mancini, Q. W. He, and J. A. Di Battista, "Tcell-derived interleukin-17 regulates the level and stability of cyclooxygenase-2 (COX-2) mRNA through restricted activation of the p38 mitogen-activated protein kinase cascade. Role of distal sequences in the $3^{\prime}$-untranslated region of COX-2 mRNA," The Journal of Biological Chemistry, vol. 278, no. 29, pp. 26897-26907, 2003.

[16] M. Laan, Z.-H. Cui, H. Hoshino et al., "Neutrophil recruitment by human IL-17 via C-X-C chemokine release in the airways," The Journal of Immunology, vol. 162, no. 4, pp. 2347-2352, 1999.

[17] Y. Komiyama, S. Nakae, T. Matsuki et al., "IL-17 plays an important role in the development of experimental autoimmune encephalomyelitis," Journal of Immunology, vol. 177, no. 1, pp. 566-573, 2006.

[18] H. R. Conti, F. Shen, N. Nayyar et al., "Th17 cells and IL-17 receptor signaling are essential for mucosal host defense against oral candidiasis," Journal of Experimental Medicine, vol. 206, no. 2, pp. 299-311, 2009.

[19] H. Chen, W. Wang, H. Xie et al., "A pathogenic role of IL17 at the early stage of corneal allograft rejection," Transplant Immunology, vol. 21, no. 3, pp. 155-161, 2009.

[20] W. J. Burlingham, R. B. Love, E. Jankowska-Gan et al., "IL-17dependent cellular immunity to collagen type $\mathrm{V}$ predisposes to obliterative bronchiolitis in human lung transplants," The Journal of Clinical Investigation, vol. 117, no. 11, pp. 3498-3506, 2007.

[21] N. Martin-Orozco, P. Muranski, Y. Chung et al., "T helper 17 cells promote cytotoxic T cell activation in tumor immunity," Immunity, vol. 31, no. 5, pp. 787-798, 2009.

[22] T. Starnes, M. J. Robertson, G. Sledge et al., "Cutting edge: IL-17F, a novel cytokine selectively expressed in activated T cells and monocytes, regulates angiogenesis and endothelial cell cytokine production," Journal of Immunology, vol. 167, no. 8, pp. 4137-4140, 2001.

[23] S. H. Chang and C. Dong, "A novel heterodimeric cytokine consisting of IL-17 and IL-17F regulates inflammatory responses," Cell Research, vol. 17, no. 5, pp. 435-440, 2007.

[24] S. Aggarwal, N. Ghilardi, M.-H. Xie, F. J. de Sauvage, and A. L. Gurney, "Interleukin-23 promotes a distinct CD4 T cell activation state characterized by the production of interleukin17," Journal of Biological Chemistry, vol. 278, no. 3, pp. 1910-1914, 2003.

[25] S. Hue, P. Ahern, S. Buonocore et al., "Interleukin-23 drives innate and T cell-mediated intestinal inflammation," Journal of Experimental Medicine, vol. 203, no. 11, pp. 2473-2483, 2006.
[26] A. V. Rachitskaya, A. M. Hansen, R. Horai et al., "Cutting edge: NKT cells constitutively express IL-23 receptor and ROR $\gamma \mathrm{t}$ and rapidly produce IL-17 upon receptor ligation in an IL-6independent fashion," Journal of Immunology, vol. 180, no. 8, pp. 5167-5171, 2008.

[27] H. H. Uhlig, B. S. McKenzie, S. Hue et al., "Differential activity of IL-12 and IL-23 in mucosal and systemic innate immune pathology," Immunity, vol. 25, no. 2, pp. 309-318, 2006.

[28] D. J. Cua and C. M. Tato, "Innate IL-17-producing cells: the sentinels of the immune system," Nature Reviews Immunology, vol. 10, no. 7, pp. 479-489, 2010.

[29] S. L. Gaffen, "Structure and signalling in the IL-17 receptor family," Nature Reviews Immunology, vol. 9, no. 8, pp. 556-567, 2009.

[30] H. Ishigame, S. Kakuta, T. Nagai et al., "Differential roles of interleukin-17A and -17F in host defense against mucoepithelial bacterial infection and allergic responses," Immunity, vol. 30, no. 1, pp. 108-119, 2009.

[31] N. Hizawa, M. Kawaguchi, S.-K. Huang, and M. Nishimura, "Role of interleukin-17F in chronic inflammatory and allergic lung disease," Clinical and Experimental Allergy, vol. 36, no. 9, pp. 1109-1114, 2006.

[32] X. O. Yang, S. H. Chang, H. Park et al., "Regulation of inflammatory responses by IL-17F," Journal of Experimental Medicine, vol. 205, no. 5, pp. 1063-1075, 2008.

[33] Y.-H. Wang, P. Angkasekwinai, N. Lu et al., "IL-25 augments type 2 immune responses by enhancing the expansion and functions of TSLP-DC-activated Th2 memory cells," The Journal of Experimental Medicine, vol. 204, no. 8, pp. 1837-1847, 2007.

[34] T. Sharkhuu, K. I. Matthaei, E. Forbes et al., "Mechanism of interleukin-25 (IL-17E)-induced pulmonary inflammation and airways hyper-reactivity," Clinical and Experimental Allergy, vol. 36, no. 12, pp. 1575-1583, 2006.

[35] J. L. Barlow and A. N. J. McKenzie, "IL-25: a key requirement for the regulation of type-2 immunity," BioFactors, vol. 35, no. 2, pp. 178-182, 2009.

[36] H. Li, J. Chen, A. Huang et al., "Cloning and characterization of IL-17B and IL-17C, two new members of the IL-17 cytokine family," Proceedings of the National Academy of Sciences of the United States of America, vol. 97, no. 2, pp. 773-778, 2000.

[37] L. van Maele, C. Carnoy, D. Cayet et al., "TLR5 signaling stimulates the innate production of IL-17 and IL-22 by CD $3{ }^{\text {neg }} \mathrm{CD} 127^{+}$ immune cells in spleen and mucosa," Journal of Immunology, vol. 185, no. 2, pp. 1177-1185, 2010.

[38] D. B. Holland, R. A. Bojar, M. D. Farrar, and K. T. Holland, "Differential innate immune responses of a living skin equivalent model colonized by Staphylococcus epidermidis or Staphylococcus aureus," FEMS Microbiology Letters, vol. 290, no. 2, pp. 149-155, 2009.

[39] Y. Yamaguchi, K. Fujio, H. Shoda et al., "IL-17B and IL$17 \mathrm{C}$ are associated with TNF- $\alpha$ production and contribute to the exacerbation of inflammatory arthritis," The Journal of Immunology, vol. 179, no. 10, pp. 7128-7136, 2007.

[40] Z. Yao, W. C. Fanslow, M. F. Seldin et al., "Herpesvirus Saimiri encodes a new cytokine, IL-17, which binds to a novel cytokine receptor," Immunity, vol. 3, no. 6, pp. 811-821, 1995.

[41] Z. Yao, M. K. Spriggs, J. M. J. Derry et al., "Molecular characterization of the human interleukin (IL)-17 receptor," Cytokine, vol. 9, no. 11, pp. 794-800, 1997. 
[42] Y. Sonobe, H. Takeuchi, K. Kataoka et al., "Interleukin-25 expressed by brain capillary endothelial cells maintains bloodbrain barrier function in a protein kinase $\mathrm{C} \varepsilon$-dependent manner," The Journal of Biological Chemistry, vol. 284, no. 46, pp. 31834-31842, 2009.

[43] S. Lajoie-Kadoch, P. Joubert, S. Létuvé et al., “TNF- $\alpha$ and IFN- $\gamma$ inversely modulate expression of the IL-17E receptor in airway smooth muscle cells," The American Journal of PhysiologyLung Cellular and Molecular Physiology, vol. 290, no. 6, pp. L1238-L1246, 2006.

[44] A. Terashima, H. Watarai, S. Inoue et al., "A novel subset of mouse NKT cells bearing the IL-17 receptor $B$ responds to IL-25 and contributes to airway hyperreactivity," Journal of Experimental Medicine, vol. 205, no. 12, pp. 2727-2733, 2008.

[45] E. A. Rickel, L. A. Siegel, P. Y. Bo-Rin et al., "Identification of functional roles for both IL-17RB and IL-17RA in mediating IL25-induced activities," The Journal of Immunology, vol. 181, no. 6, pp. 4299-4310, 2008.

[46] R. E. Kuestner, D. W. Taft, A. Haran et al., "Identification of the IL-17 receptor related molecule IL-17RC as the receptor for IL17F," The Journal of Immunology, vol. 179, no. 8, pp. 5462-5473, 2007.

[47] D. Ge and Z. You, "Expression of interleukin-17RC protein in normal human tissues," International Archives of Medicine, vol. 1, no. 1, article 19, 2008.

[48] Z. Rong, A. Wang, Z. Li et al., "IL-17RD (Sef or IL-17RLM) interacts with IL-17 receptor and mediates IL-17 signaling," Cell Research, vol. 19, no. 2, pp. 208-215, 2009.

[49] T.-S. Li, X.-N. Li, Z.-J. Chang, X.-Y. Fu, and L. Liu, "Identification and functional characterization of a novel interleukin 17 receptor: a possible mitogenic activation through ras/mitogenactivated protein kinase signaling pathway," Cellular Signalling, vol. 18, no. 8, pp. 1287-1298, 2006.

[50] T. A. Moseley, D. R. Haudenschild, L. Rose, and A. H. Reddi, "Interleukin-17 family and IL-17 receptors," Cytokine and Growth Factor Reviews, vol. 14, no. 2, pp. 155-174, 2003.

[51] A. Hot and P. Miossec, "Effects of interleukin (IL)-17A and IL$17 \mathrm{~F}$ in human rheumatoid arthritis synoviocytes," Annals of the Rheumatic Diseases, vol. 70, no. 5, pp. 727-732, 2011.

[52] S. Zhu, W. Pan, P. Shi et al., "Modulation of experimental autoimmune encephalomyelitis through TRAF3-mediated suppression of interleukin 17 receptor signaling," The Journal of Experimental Medicine, vol. 207, no. 12, pp. 2647-2662, 2010.

[53] L. Zhao, Y. Tang, Z. You et al., "Interleukin-17 contributes to the pathogenesis of autoimmune hepatitis through inducing hepatic interleukin-6 expression," PLoS ONE, vol. 6, no. 4, Article ID e18909, 2011.

[54] H. Yu, J. Huang, Y. Liu et al., "IL-17 contributes to autoimmune hepatitis," Journal of Huazhong University of Science and Technology [Medical Sciences], vol. 30, no. 4, pp. 443-446, 2010.

[55] C. R. Grant, R. Liberal, B. S. Holder et al., "Dysfunctional $\mathrm{CD} 39^{P O S}$ regulatory $\mathrm{T}$ cells and aberrant control of T-helper type 17 cells in autoimmune hepatitis," Hepatology, vol. 59, no. 3, pp. 1007-1015, 2014.

[56] M. S. Longhi, R. Liberal, B. Holder et al., "Inhibition of interleukin-17 promotes differentiation of $\mathrm{CD} 25^{-}$cells into stable T regulatory cells in patients with autoimmune hepatitis," Gastroenterology, vol. 142, no. 7, pp. 1526.e6-1535.e6, 2012.

[57] M. P. Manns, A. J. Czaja, J. D. Gorham et al., "Diagnosis and management of autoimmune hepatitis," Hepatology, vol. 51, no. 6, pp. 2193-2213, 2010.
[58] C. Qian, T. Jiang, W. Zhang et al., "Increased IL-23 and IL-17 expression by peripheral blood cells of patients with primary biliary cirrhosis," Cytokine, vol. 64, no. 1, pp. 172-180, 2013.

[59] R. Y. Z. Lan, T. L. Salunga, K. Tsuneyama et al., "Hepatic IL17 responses in human and murine primary biliary cirrhosis," Journal of Autoimmunity, vol. 32, no. 1, pp. 43-51, 2009.

[60] K. Harada, S. Shimoda, Y. Sato, K. Isse, H. Ikeda, and Y. Nakanuma, "Periductal interleukin-17 production in association with biliary innate immunity contributes to the pathogenesis of cholangiopathy in primary biliary cirrhosis," Clinical and Experimental Immunology, vol. 157, no. 2, pp. 261-270, 2009.

[61] C.-Y. Yang, X. Ma, K. Tsuneyama et al., "IL-12/Th1 and IL23/Th17 biliary microenvironment in primary biliary cirrhosis: implications for therapy," Hepatology, vol. 59, no. 5, pp. 19441953, 2014.

[62] K. Harada, S. Shimoda, H. Ikeda et al., "Significance of periductal Langerhans cells and biliary epithelial cell-derived macrophage inflammatory protein- $3 \alpha$ in the pathogenesis of primary biliary cirrhosis," Liver International, vol. 31, no. 2, pp. 245-253, 2011.

[63] W. Hsu, W. Zhang, K. Tsuneyama et al., "Differential mechanisms in the pathogenesis of autoimmune cholangitis versus inflammatory bowel disease in interleukin-2 $\mathrm{R} \alpha^{-1-}$ mice," Hepatology, vol. 49, no. 1, pp. 133-140, 2009.

[64] K. Kawata, M. Tsuda, G.-X. Yang et al., "Identification of potential cytokine pathways for therapeutic intervention in murine primary biliary cirrhosis," PLoS ONE, vol. 8, no. 9, Article ID e74225, 2013.

[65] C.-Y. Yang, P. S. C. Leung, G.-X. Yang et al., "Epitope-specific anti-nuclear antibodies are expressed in a mouse model of primary biliary cirrhosis and are cytokine-dependent," Clinical and Experimental Immunology, vol. 168, no. 3, pp. 261-267, 2012.

[66] J. Katt, D. Schwinge, T. Schoknecht et al., "Increased T helper type 17 response to pathogen stimulation in patients with primary sclerosing cholangitis," Hepatology, vol. 58, no. 3, pp. 1084-1093, 2013.

[67] H. Kulaksiz, G. Rudolph, P. Kloeters-Plachky, P. Sauer, H. Geiss, and A. Stiehl, "Biliary candida infections in primary sclerosing cholangitis," Journal of Hepatology, vol. 45, no. 5, pp. 711-716, 2006.

[68] F. Meng, K. Wang, T. Aoyama et al., "Interleukin-17 signaling in inflammatory, Kupffer cells, and hepatic stellate cells exacerbates liver fibrosis in mice," Gastroenterology, vol. 143, no. 3, pp. 765-776, 2012.

[69] M. Hara, H. Kono, S. Furuya, K. Hirayama, M. Tsuchiya, and H. Fujii, "Interleukin-17A plays a pivotal role in cholestatic liver fibrosis in mice," Journal of Surgical Research, vol. 183, no. 2, pp. 574-582, 2013.

[70] Y. Zheng, D. M. Danilenko, P. Valdez et al., "Interleukin-22, a $\mathrm{T}_{H} 17$ cytokine, mediates IL-23-induced dermal inflammation and acanthosis," Nature, vol. 445, no. 7128, pp. 648-651, 2007.

[71] A. Ogawa, A. Andoh, Y. Araki, T. Bamba, and Y. Fujiyama, "Neutralization of interleukin-17 aggravates dextran sulfate sodium-induced colitis in mice," Clinical Immunology, vol. 110, no. 1, pp. 55-62, 2004.

[72] E. Lubberts, M. I. Koenders, B. Oppers-Walgreen et al., "Treatment with a neutralizing anti-murine interleukin-17 antibody after the onset of collagen-induced arthritis reduces joint inflammation, cartilage destruction, and bone erosion," Arthritis and Rheumatism, vol. 50, no. 2, pp. 650-659, 2004. 
[73] H.-C. Hsu, P. Yang, J. Wang et al., "Interleukin 17-producing T helper cells and interleukin 17 orchestrate autoreactive germinal center development in autoimmune BXD2 mice," Nature Immunology, vol. 9, no. 2, pp. 166-175, 2008.

[74] M. S. Longhi, Y. Ma, G. Mieli-Vergani, and D. Vergani, "Aetiopathogenesis of autoimmune hepatitis," Journal of Autoimmunity, vol. 34, no. 1, pp. 7-14, 2010.

[75] I. N. Crispe, “The liver as a lymphoid organ," Annual Review of Immunology, vol. 27, pp. 147-163, 2009.

[76] M. S. Longhi, M. J. Hussain, R. R. Mitry et al., "Functional study of $\mathrm{CD} 4^{+} \mathrm{CD} 25^{+}$regulatory $\mathrm{T}$ cells in health and autoimmune hepatitis," The Journal of Immunology, vol. 176, no. 7, pp. 44844491, 2006.

[77] S. Ferri, M. S. Longhi, C. de Molo et al., "A multifaceted imbalance of T cells with regulatory function characterizes type 1 autoimmune hepatitis," Hepatology, vol. 52, no. 3, pp. 999-1007, 2010.

[78] S. Sakaguchi, K. Fukuma, K. Kuribayashi, and T. Masuda, "Organ-specific autoimmune diseases induced in mice by elimination of T cell subset. I. Evidence for the active participation of $\mathrm{T}$ cells in natural self-tolerance; deficit of a $\mathrm{T}$ cell subset as a possible cause of autoimmune disease," The Journal of Experimental Medicine, vol. 161, no. 1, pp. 72-87, 1985.

[79] J. M. Fletcher, R. Lonergan, L. Costelloe et al., "CD39+ Foxp $3^{+}$ regulatory $\mathrm{T}$ cells suppress pathogenic Th17 cells and are impaired in multiple sclerosis," Journal of Immunology, vol. 183, no. 11, pp. 7602-7610, 2009.

[80] M. S. Longhi, F. Meda, P. Wang et al., "Expansion and de novo generation of potentially therapeutic regulatory $\mathrm{T}$ cells in patients with autoimmune hepatitis," Hepatology, vol. 47, no. 2, pp. 581-591, 2008.

[81] P. Invernizzi, C. Selmi, and M. E. Gershwin, "Update on primary biliary cirrhosis," Digestive and Liver Disease, vol. 42, no. 6, pp. 401-408, 2010.

[82] K. D. Lindor, M. E. Gershwin, R. Poupon, M. Kaplan, N. V. Bergasa, and E. J. Heathcote, "Primary biliary cirrhosis," Hepatology, vol. 50, no. 1, pp. 291-308, 2009.

[83] G. Syal, M. Fausther, and J. A. Dranoff, "Advances in cholangiocyte immunobiology," The American Journal of PhysiologyGastrointestinal and Liver Physiology, vol. 303, no. 10, pp. G1077G1086, 2012.

[84] G. Ballardini, M. Fallani, F. B. Bianchi, and E. Pisi, "Antigen presenting cells in liver biopsies from patients with primary biliary cirrhosis," Autoimmunity, vol. 3, no. 2, pp. 135-144, 1989.

[85] S. Oertelt, Z.-X. Lian, C.-M. Cheng et al., "Anti-mitochondrial antibodies and primary biliary cirrhosis in TGF- $\beta$ receptor II dominant-negative mice," The Journal of Immunology, vol. 177, no. 3, pp. 1655-1660, 2006.

[86] M. Nakamura, H. Kondo, T. Mori et al., "Anti-gp210 and anti-centromere antibodies are different risk factors for the progression of primary biliary cirrhosis," Hepatology, vol. 45, no. 1, pp. 118-127, 2007.

[87] S. Itoh, T. Ichida, T. Yoshida et al., "Autoantibodies against a 210 $\mathrm{kDa}$ glycoprotein of the nuclear pore complex as a prognostic marker in patients with primary biliary cirrhosis," Journal of Gastroenterology and Hepatology, vol. 13, no. 3, pp. 257-265, 1998.

[88] Y.-M. Lee and M. M. Kaplan, "Primary sclerosing cholangitis," The New England Journal of Medicine, vol. 332, no. 14, pp. 924933, 1995.

[89] P. Angulo and K. D. Lindor, "Primary sclerosing cholangitis," Hepatology, vol. 30, no. 1, pp. 325-332, 1999.
[90] J. E. Eaton, J. A. Talwalkar, K. N. Lazaridis, G. J. Gores, and K. D. Lindor, "Pathogenesis of primary sclerosing cholangitis and advances in diagnosis and management," Gastroenterology, vol. 145, no. 3, pp. 521-536, 2013.

[91] G. M. Hirschfield, T. H. Karlsen, K. D. Lindor, and D. H. Adams, "Primary sclerosing cholangitis," The Lancet, vol. 382, no. 9904, pp. 1587-1599, 2013.

[92] G. Rudolph, D. Gotthardt, P. Klöters-Plachky, H. Kulaksiz, D. Rost, and A. Stiehl, "Influence of dominant bile duct stenoses and biliary infections on outcome in primary sclerosing cholangitis," Journal of Hepatology, vol. 51, no. 1, pp. 149-155, 2009.

[93] P. Fickert, G. Zollner, A. Fuchsbichler et al., "Ursodeoxycholic acid aggravates bile infarcts in bile duct-ligated and Mdr2 knockout mice via disruption of cholangioles," Gastroenterology, vol. 123, no. 4, pp. 1238-1251, 2002.

[94] M. J. Pollheimer, M. Trauner, and P. Fickert, "Will we ever model PSC?- 'it's hard to be a PSC model!'”' Clinics and Research in Hepatology and Gastroenterology, vol. 35, no. 12, pp. 792-804, 2011.

[95] A. Chiricozzi, E. Guttman-Yassky, M. Suárez-Farĩas et al., "Integrative responses to IL-17 and TNF- $\alpha$ in human keratinocytes account for key inflammatory pathogenic circuits in psoriasis," Journal of Investigative Dermatology, vol. 131, no. 3, pp. 677-687, 2011.

[96] S. Fujino, A. Andoh, S. Bamba et al., "Increased expression of interleukin 17 in inflammatory bowel disease," Gut, vol. 52, no. 1, pp. 65-70, 2003.

[97] S. Kotake, N. Udagawa, N. Takahashi et al., "IL-17 in synovial fluids from patients with rheumatoid arthritis is a potent stimulator of osteoclastogenesis," The Journal of Clinical Investigation, vol. 103, no. 9, pp. 1345-1352, 1999.

[98] G. Dong, R. Ye, W. Shi et al., "IL-17 induces autoantibody overproduction and peripheral blood mononuclear cell overexpression of IL-6 in lupus nephritis patients," Chinese Medical Journal, vol. 116, no. 4, pp. 543-548, 2003.

[99] S. Zhu and Y. Qian, "IL-17/IL-17 receptor system in autoimmune disease: mechanisms and therapeutic potential," Clinical Science, vol. 122, no. 11, pp. 487-511, 2012.

[100] K. A. Papp, R. G. Langley, B. Sigurgeirsson et al., "Efficacy and safety of secukinumab in the treatment of moderate-tosevere plaque psoriasis: a randomized, double-blind, placebocontrolled phase II dose-ranging study," British Journal of Dermatology, vol. 168, no. 2, pp. 412-421, 2013.

[101] C. Leonardi, R. Matheson, C. Zachariae et al., "Anti-interleukin17 monoclonal antibody ixekizumab in chronic plaque psoriasis," The New England Journal of Medicine, vol. 366, no. 13, pp. 1190-1191, 2012.

[102] K. A. Papp, C. Leonardi, A. Menter et al., "Brodalumab, an anti-interleukin-17-receptor antibody for psoriasis," The New England Journal of Medicine, vol. 366, no. 13, pp. 1181-1189, 2012.

[103] M. T. Tse, "IL-17 antibodies gain momentum," Nature Reviews Drug Discovery, vol. 12, no. 11, pp. 815-816, 2013.

[104] M. C. Genovese, P. Durez, H. B. Richards et al., "Efficacy and safety of secukinumab in patients with rheumatoid arthritis: a phase II, dose-finding, double-blind, randomised, placebo controlled study," Annals of the Rheumatic Diseases, vol. 72, no. 6, pp. 863-869, 2013.

[105] D. Baeten, X. Baraliakos, J. Braun et al., "Anti-interleukin-17A monoclonal antibody secukinumab in treatment of ankylosing spondylitis: a randomised, double-blind, placebo-controlled trial," The Lancet, vol. 382, pp. 1705-1713, 2013. 
[106] A. D. Dick, I. Tugal-Tutkun, S. Foster et al., "Secukinumab in the treatment of noninfectious uveitis: results of three randomized, controlled clinical trials," Ophthalmology, vol. 120, no. 4, pp. 777-787, 2013.

[107] M. C. Genovese, M. Greenwald, C. S. Cho et al., "A phase II randomized study of subcutaneous ixekizumab, an antiinterleukin-17 monoclonal antibody, in rheumatoid arthritis patients who were naive to biologic agents or had an inadequate response to tumor necrosis factor inhibitors," Arthritis \& Rheumatism, vol. 66, no. 7, pp. 1693-1704, 2014.

[108] W. Hueber, B. E. Sands, S. Lewitzky et al., "Secukinumab, a human anti-IL-17A monoclonal antibody, for moderate to severe Crohn's disease: Unexpected results of a randomised, double-blindplacebo-controlled trial," Gut, vol. 61, no. 12, pp. 1693-1700, 2012.

[109] D. Toy, D. Kugler, M. Wolfson et al., "Cutting edge: interleukin 17 signals through a heteromeric receptor complex," Journal of Immunology, vol. 177, no. 1, pp. 36-39, 2006.

[110] S. Zrioual, M.-L. Toh, A. Tournadre et al., "IL-17RA and IL17RC receptors are essential for IL-17A-induced $\mathrm{ELR}^{+} \mathrm{CXC}$ chemokine expression in synoviocytes and are overexpressed in rheumatoid blood," Journal of Immunology, vol. 180, no. 1, pp. 655-663, 2008.

[111] R. Pappu, V. Ramirez-Carrozzi, N. Ota, W. Ouyang, and Y. Hu, "The IL-17 family cytokines in immunity and disease," Journal of Clinical Immunology, vol. 30, no. 2, pp. 185-195, 2010.

[112] C. Ritchlin, P. Rahman, A. Kavanaugh et al., "Efficacy and safety of the anti-IL-12/23 p40 monoclonal antibody, ustekinumab, in patients with active psoriatic arthritis despite conventional nonbiological and biological anti-tumour necrosis factor therapy: 6-month and 1-year results of the phase 3, multicentre, doubleblind, placebo-controlled," Annals of the Rheumatic Diseases, vol. 73, no. 6, pp. 990-999, 2014.

[113] W. J. Sandborn, C. Gasink, L.-L. Gao et al., "Ustekinumab induction and maintenance therapy in refractory Crohn's disease," The New England Journal of Medicine, vol. 367, no. 16, pp. 15191528, 2012.

[114] C. E. M. Griffiths, B. E. Strober, P. van de Kerkhof et al., "Comparison of ustekinumab and etanercept for moderate-tosevere psoriasis," The New England Journal of Medicine, vol. 362, no. 2, pp. 118-128, 2010.

[115] K. A. Papp, C. E. M. Griffiths, K. Gordon et al., "Long-term safety of ustekinumab in patients with moderate-to-severe psoriasis: final results from 5 years of follow-up," British Journal of Dermatology, vol. 168, no. 4, pp. 844-854, 2013.

[116] P. Miossec and J. K. Kolls, "Targeting IL-17 and $\mathrm{T}_{H} 17$ cells in chronic inflammation," Nature Reviews Drug Discovery, vol. 11, no. 10, pp. 763-776, 2012.

[117] A. Shetty, R. Hanson, P. Korsten et al., "Tocilizumab in the treatment of rheumatoid arthritis and beyond," Drug Design, Development and Therapy, vol. 8, pp. 349-364, 2014.

[118] J. E. Frampton, "Tocilizumab: a review of its use in the treatment of juvenile idiopathic arthritis," Pediatric Drugs, vol. 15, no. 6, pp. 515-531, 2013.

[119] M. Geyer and U. Müller-Ladner, "Actual status of antiinterleukin-1 therapies in rheumatic diseases," Current Opinion in Rheumatology, vol. 22, no. 3, pp. 246-251, 2010.

[120] J. R. Huh, E. E. Englund, H. Wang et al., "Identification of potent and selective diphenylpropanamide ROR $\gamma$ inhibitors," ACS Medicinal Chemistry Letters, vol. 4, no. 1, pp. 79-84, 2013.
[121] P. M. Khan, B. E.-D. M. El-Gendy, N. Kumar et al., "Small molecule amides as potent ROR- $\gamma$ selective modulators," Bioorganic and Medicinal Chemistry Letters, vol. 23, no. 2, pp. 532536, 2013.

[122] S. C. P. Williams, "Flurry of deal-making surrounds new autoimmunity target," Nature Medicine, vol. 19, no. 9, article 1078, 2013.

[123] L. A. Solt, N. Kumar, P. Nuhant et al., "Suppression of TH17 differentiation and autoimmunity by a synthetic ROR ligand," Nature, vol. 472, no. 7344, pp. 491-494, 2011.

[124] P. Delerive, W. W. Chin, and C. S. Suen, "Identification of Reverb $\alpha$ as a novel ROR $\alpha$ target gene," Journal of Biological Chemistry, vol. 277, no. 38, pp. 35013-35018, 2002.

[125] J. Wang, L. Yin, and M. A. Lazar, “The orphan nuclear receptor Rev-erb $\alpha$ regulates circadian expression of plasminogen activator inhibitor type 1," The Journal of Biological Chemistry, vol. 281, no. 45, pp. 33842-33848, 2006.

[126] T. Wada, S. K. Hong, M. Angers et al., "Identification of oxysterol $7 \alpha$-hydroxylase (Cyp7b1) as a novel retinoid-related orphan receptor $\alpha(\mathrm{ROR} \alpha)$ (NR1F1) target gene and a functional cross-talk between ROR $\alpha$ and liver X receptor (NR1H3)," Molecular Pharmacology, vol. 73, no. 3, pp. 891-899, 2008.

[127] N. Kumar, B. Lyda, M. R. Chang et al., "Identification of SR2211: a potent synthetic ROR $\gamma$-selective modulator," ACS Chemical Biology, vol. 7, no. 4, pp. 672-677, 2012.

[128] E. ELinghaus, D. ELinghaus, P. E. Stuart et al., "Genome-wide asociation study identifies a psoriasis susceptibility locus at TRAF3IP2," Nature Genetics, vol. 42, no. 11, pp. 991-995, 2010.

[129] U. Hüffmeier, S. Uebe, A. B. Ekici et al., "CoMon variants at TRAF3IP2 are aSociated with susceptibility to psoriatic arthritis and psoriasis," Nature Genetics, vol. 42, no. 11, pp. 996-999, 2010.

[130] C. Liu, S. Swaidani, W. Qian et al., "A CC' loop decoy peptide blocks the interaction between Actl and IL-17RA to attenuate IL-17- and IL-25-induced inflammation," Science Signaling, vol. 4, no. 197, article ra72, 2011.

[131] F. Shen and S. L. Gaffen, "Structure-function relationships in the IL-17 receptor: implications for signal transduction and therapy," Cytokine, vol. 41, no. 2, pp. 92-104, 2008. 


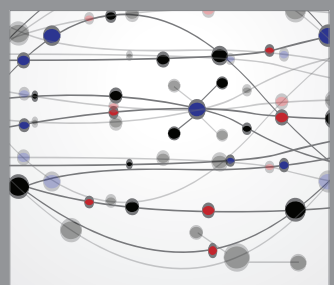

The Scientific World Journal
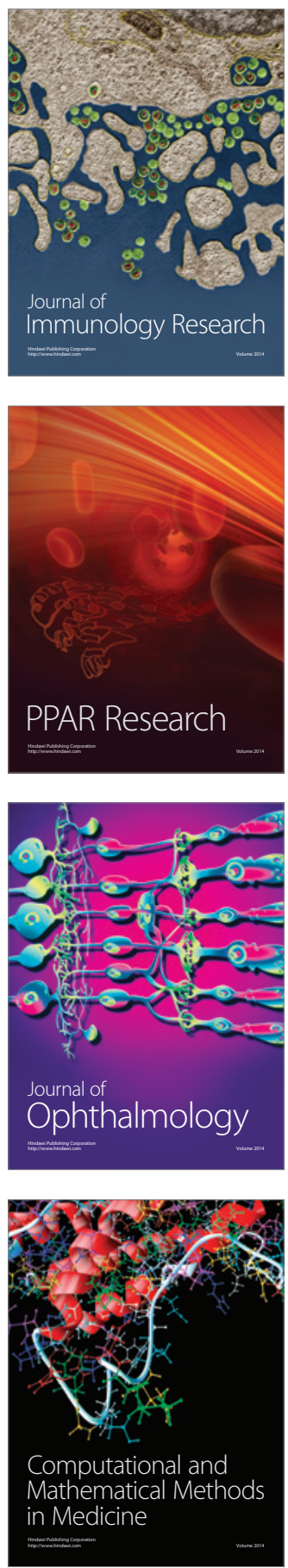

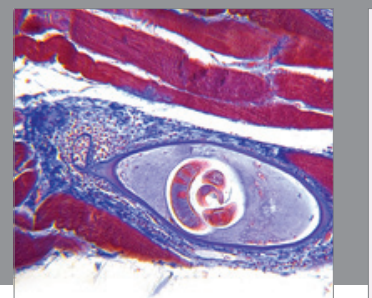

Gastroenterology

Research and Practice
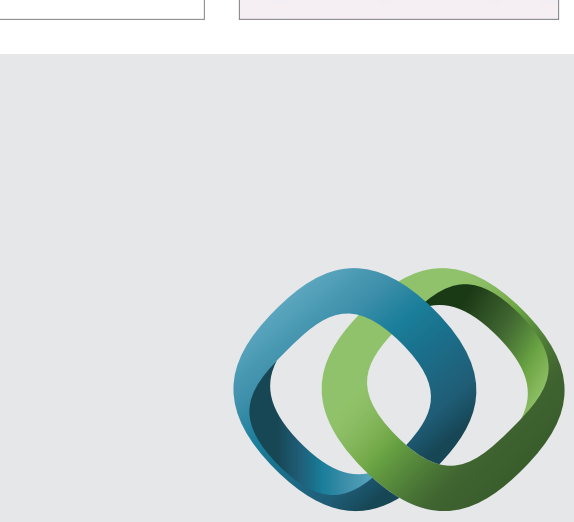

\section{Hindawi}

Submit your manuscripts at

http://www.hindawi.com
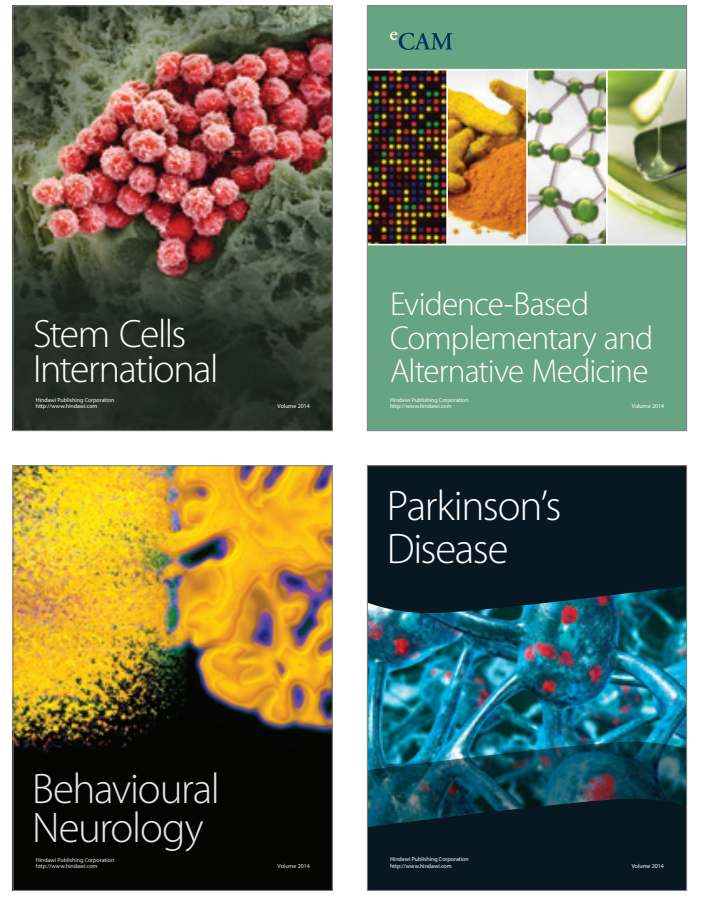
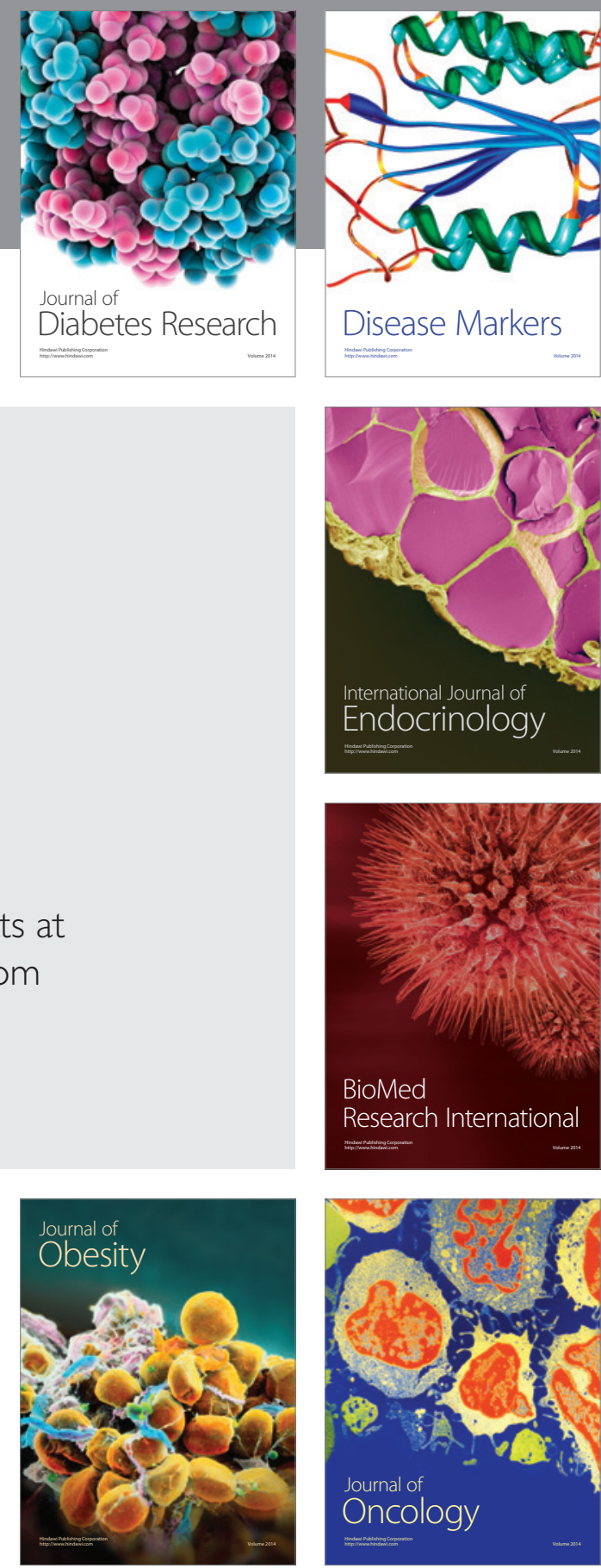

Disease Markers
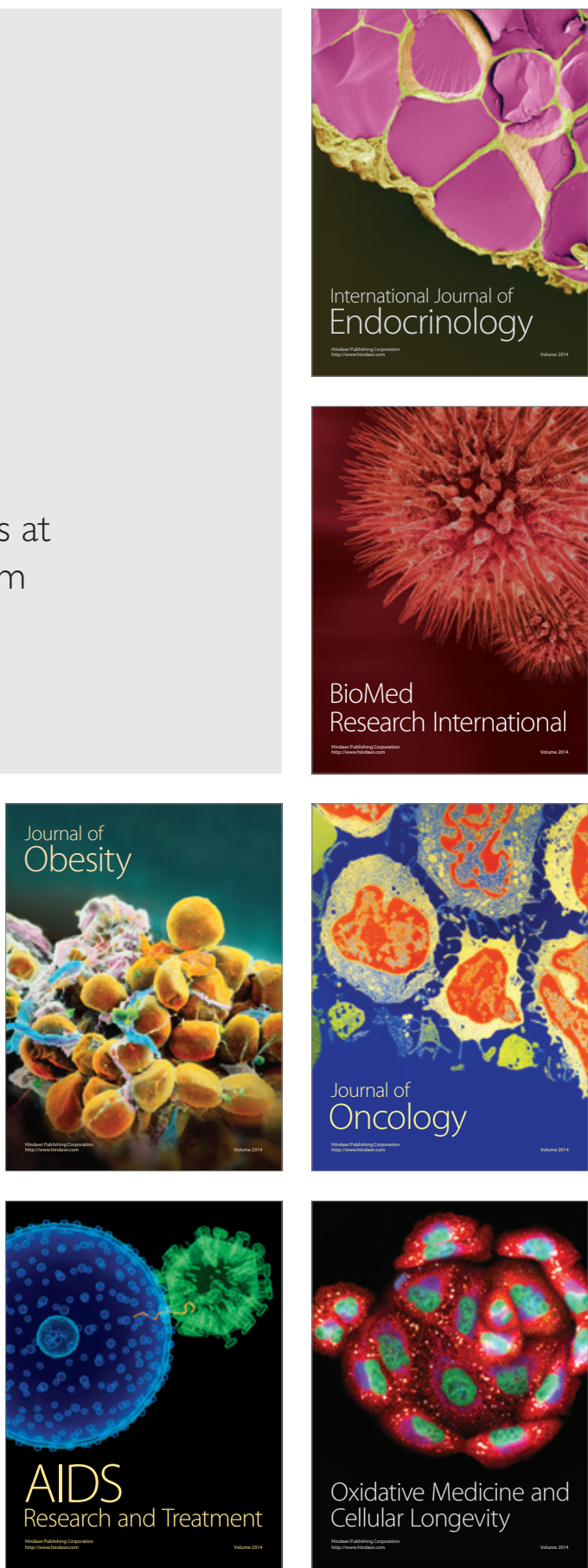